\title{
AVALIAÇÃO EDUCACIONAL: TENDÊNCIAS EM ESTUDOS DA ÁREA DA EDUCAÇÃO (2015-2018)
}

\author{
EDUCATIONAL EVALUATION: TRENDS IN EDUCATION STUDIES (2015-2018) \\ EVALUACION EDUCATIVA: TENDENCIAS EN ESTUDIOS EDUCATIVOS (2015-2018)
}

\author{
Mônica Tessaro 1 \\ Fernanda dos Santos Paulo2
}

\begin{abstract}
RESUMO
Neste estudo apresentamos a disseminação dos conhecimentos sobre o tema avaliação educacional e suas tendências temáticas recorrentes à luz dos conhecimentos apresentados no portal dos periódicos CAPES, referentes ao triênio 2015-2018. Diante disso flagramos a recorrência de duas categorias que colocam em tela a avalição educacional como sendo um tema candente estres as pesquisas contemporâneas, sendo elas: avaliação da educação básica e avaliação do ensino superior. A partir das interpretações possibilitadas pela pesquisa, constatamos que a avaliação educacional permanece ancorada na lógica mercantilista de mercado, através da valorização dos instrumentos de avaliação em larga escala, mediados pelos organismos internacionais.
\end{abstract}

PALAVRAS-CHAVE: Avaliação educacional. Avaliação da educação básica. Avaliação do ensino superior.

\begin{abstract}
In this study we present the dissemination of knowledge about the theme of educational evaluation and its recurring thematic trends in the light of the knowledge presented in the portal of CAPES journals, referring to the 2015-2018 triennium. Thus, we have caught the recurrence of two categories that put on screen the educational evaluation as being a theme of contemporary research, such as: evaluation of basic education and evaluation of higher education. Based on the interpretations made possible by the research, we found that the educational evaluation remains anchored in market logic, through the valuation of large-scale assessment instruments, mediated by the organisms International. .
\end{abstract}

KEYWORDS: Educational evaluation. Evaluation of basic education. Evaluation of higher education.

\section{RESUMEN}

En este estudio presentamos la difusión del conocimiento sobre el tema de la evaluación educativa y sus tendencias temáticas recurrentes a la luz de los conocimientos presentados en el portal de revistas CAPES,

\footnotetext{
${ }^{1}$ Mestra em Educação pelo Programa de Pós Graduação em Educação (PPGE) pela Universidade Comunitária da Região de Chapecó (UNOCHAPECÓ). Doutoranda em Educação Programa de Pós Graduação em Educação (PPGEd) da Universidade do Oeste de Santa Catarina (UNOESC)

2 Professora do Curso de Pós-Graduação em Educação da UNOESC/Joaçaba-SC. Militante da Educação Popular pela AEPPA e MEP. Pedagoga, especialista em Educação Popular e Movimentos Sociais e mestre em Educação.
} 
refiriéndose al trienio 2015-2018. Así, hemos captado la recurrencia de dos categorías que ponen en pantalla la evaluación educativa como un tema de la investigación contemporánea, tales como: evaluación de la educación básica y evaluación de la educación superior. Sobre la base de las interpretaciones que ha hecho posible la investigación, constatamos que la evaluación educativa sigue anclada en la lógica del mercado, mediante la valoración de instrumentos de evaluación a gran escala, mediados por los organismos Internacional.

PALABRAS CLAVE: Evaluación educativa. Evaluación de la educación básica. Evaluación de la educación superior.

\section{CONSIDERAÇÕES INICIAIS}

No cenário mundial, a década de 90 do século XX foi marcada pelo fenômeno da mundialização do capital e suas repercussões na intervenção estatal, que gerou transformações políticas e econômicas impulsionando reformas do aparelho do Estado, atingindo grande parte do mundo do capital. Essas reformas reconfiguraram o papel do Estado, pois o tornaram um grande agente do mercado consumidor, facilitando a reprodução do capitalismo, além da repercussão de forma acentuada no campo social que, conforme Behring (2008), deixaram marcas indeléveis em todos os segmentos da sociedade, agindo "como força coesiva das classes dirigentes" (GRAMSCI, 1999, p. 115).

Sob o ponto de vista administrativo dos reformadores, era preciso transformar o Estado burocrático em um Estado gerencialista, por meio da implantação de uma gestão responsável direcionada para o alcance de resultados. Para Bresser Pereira (2010, p.116), idealizador das reformas no Brasil, uma das consequências "foi a distinção entre atividades exclusivas do Estado, que envolvem poder de Estado, e as atividades não exclusivas, que devem ser realizadas por organizações públicas não estatais".

A esse respeito, Simionatto e Luza (2011) sintetizam que, a partir das reformas, o Estado redefiniu seu papel sob a ideologia neoliberal permanecendo forte economicamente, pois contou com as privatizações, abertura comercial e estabilidade monetária, mas se ausentou dos gastos sociais, transferindo suas responsabilidades para a sociedade civil. Assim, o Estado e o mercado alargam seus laços, permanecendo inter-relacionados.

De acordo com Barroso (2005), é nesta arena de debate que foi delineada a reforma educacional no Brasil, com objetivo de conciliar os modelos internacionais para a construção de uma nova proposta de gestão da educação. A partir da reforma, ocorreu a promoção de medidas políticas administrativas que alteraram o modelo de regulação do poder público no contexto escolar. Entre as implicações desse processo, destaca-se a efetivação de programas que 
controlam resultados e avaliam a performance de alunos e instituições (ALMEIDA JÚNIOR, 2001). Significa dizer que a educação foi ajustada ao cenário de mudanças da nova conjuntura, ou seja, as novas perspectivas da educação, influenciadas pela reforma do Estado, resultaram no desenvolvimento de políticas educacionais sintonizadas com a ideologia neoliberal.

Nesse contexto, a avaliação educacional assume a condição de instrumento estratégico para atender demandas mercadológicas, pois há uma flexibilização dos processos educativos e, em contrapartida, acentua-se o rigor na avaliação por resultados com vistas ao alcance de um padrão de qualidade. De acordo com Krawczyk e Vieira (2012, p.59), foi para atender a esses critérios que ocorreu a implantação de um sistema institucional de avaliação comum para todo país, centralizado no Ministério da Educação (MEC), que "introduziu a avaliação externa do desempenho do aluno, abrangendo os diferentes níveis de ensino".

É válido ressaltar a existência do enfoque positivista e classificatório das práticas avaliativas (DEMO, 1995; LUCKESI, 1995), consubstanciadas pelas pedagogias tradicional e tecnicista. Os referidos autores destacam a forte influência que os organismos internacionais, os modelos seriados de produção e outras instituições de cunho privado desempenham nas escolas, clarificando as evidências de condicionamento dos processos avaliativos que objetivam a produção de resultados como fins.

Considerando essa breve digressão histórica, é notória uma tendente valorização da eficiência e eficácia, por parte da administração pública brasileira, no que diz respeito à avaliação educacional. Examinar uma demarcação como essa, constitui, portanto, medida útil para compreender objetivos e dinâmicas que, na atualidade, dão lugar à referida valorização. Essa compreensão nos mobilizou a acessar aos temas atuais de pesquisa na área da Educação, tendo por objetivo analisar tendências dos estudos da área sobre avaliação educacional, publicados no triênio 2015-2018, tendo em vista as temáticas mais abordadas e contribuições dos estudos para a comunidade científica.

Realizamos, portanto, levantamento dos dados, segundo pressupostos da pesquisa qualitativa e enfoque na revisão bibliográfica. Consultamos os periódicos da base Qualis Periódicos da Coordenação de Aperfeiçoamento de Pessoal de Nível Superior (Capes), da área da Educação e avaliados em 2017. O levantamento iniciou no mês de agosto de 2018 e se estendeu até o mês de outubro do mesmo ano. Nessa primeira etapa chegamos aos seguintes temas com maior recorrência entre as pesquisas: Formação de professores, Gestão educacional; Avaliação educacional; Formação profissional; Financiamento educacional; Educação em tempo integral e Currículo. 
Na segunda etapa, escolhemos o tema avaliação educacional para aprofundar nosso estudo. Sendo assim, identificamos os assuntos relacionados à avaliação educacional publicados no triênio 2015-2018, que permitiram, entre outros aspectos, inaugurar as tendências na produção do conhecimento sobre a referida temática. Neste artigo, quando nos referimos às tendências, queremos dar lugar aos enfoques dos autores de fundo, de que se servem os autores dos trabalhos, ou seja, iremos priorizar na discussão as contribuições dos autores que são referências na área da avaliação educacional.

Consoante ao objetivo anunciado, iniciamos com uma breve contextualização acerca da reforma dos anos 90 do século XX e as características do papel regulador que o Estado passou a exercer por meio de um sistema de avaliação educacional externo, utilizado como estratégia de regulação da qualidade. Na sequência, apresentamos o processo e os resultados do levantamento, seguidos de análises orientadas em dois eixos temáticos: avaliação da educação básica e avaliação da educação superior. Por fim, tecemos algumas considerações acerca da temática na interface com as principais tendências investigativas da área referentes ao último triênio, com vistas a contribuir com o conhecimento científico na área.

\section{Avaliação educacional: contextualizando o tema no cenário nacional}

A atual crise do sistema capitalista teve início ainda nos anos 70 do século passado, motivada pela falência mundial do modelo fordista-keynesiano. O Brasil alcança os anos 80 desse mesmo século, no plano internacional, com uma reação burguesa à crise do capital. Assim, a década de 80 termina com uma situação econômica vizinha à hiperinflação.

A entrada nos anos 90 estampou um país destruído pela inflação, fermento para a instalação da hegemonia neoliberal. A estratégia emblemática então lançada com vistas ao alcance de uma sociedade moderna foi a Reforma do Aparelho do Estado, que teve como principal característica alterar o paradigma vigente no que se refere ao papel a ser desempenhado pelo Estado (BEHRING, 2008). Para implementar a concepção de um Estado "forte", algumas providências precisariam ser tomadas:

\footnotetext{
É preciso, agora, dar um salto adiante, no sentido de uma administração pública que chamaria de "gerencial", baseada em conceitos atuais de administração e eficiência, voltada para o controle dos resultados e descentralizada para poder chegar ao cidadão, que, numa sociedade democrática, é quem dá legitimidade às instituições e que, portanto, se torna "cliente privilegiado" dos serviços prestados pelo Estado (BRASIL,1995, p.07).
} 
Assim, sob a perspectiva gerencial, as novas formas de regulação pelo Estado tiveram em vista introduzir "a eficiência e a qualidade como cultura na administração pública, inspirada em elementos da gestão empresarial. O controle se faz pelos resultados e não pelos processos [...]" (BEHRING, 2008, p. 179). Essas novas regulações incidiram, sobretudo, no campo da gestão, do financiamento e da avaliação educacional, estabelecendo regras, normas e instrumentos controladores.

Para Maroy e Dupriez (2000), a regulação pode ser entendida por diferentes ângulos, mas, em seu sentido mais amplo, refere-se ao controle de ações exercido por uma instituição reconhecida (governo, uma agência estatal ou hierarquia de uma organização) para orientar diferentes atores sobre quem ela exerce alguma autoridade. Assim, a regulação pode ser entendida como um processo social que dita "as regras do jogo", pois apresenta um conjunto de mecanismos para o controle, por meio do qual um sistema busca manter o equilíbrio, ou orientar as ações dos sujeitos.

De acordo com Lessard (2006, p. 205), não podemos perder de vista que a regulação pode ser representada "como um conjunto que supervisiona, regulamentando e dominando uma prática que o Estado deseja tornar mais eficaz", ou seja, é a realização de um ajuste nos sistemas que estabelece regras de acordo com o Estado e o mercado, buscando atender aos interesses mercantilistas. Para os reformadores, inspirados nos modelos internacionais com vistas a tornar 0 Estado gerencialista, há que se reformar o Estado, "tendo em vista recuperar a governabilidade (legitimidade) e a governance (capacidade financeira e administrativa de governar)" (BEHRING, 2008, p. 173).

Para Maroy e Dupriez (2010) esse modelo pode ser chamado de Estado avaliador ou governança pelos resultados. O Estado avaliador não é estruturado sobre os elementos da racionalidade, características típicas do Estado burocrático, mas sobre os resultados, a partir da busca pela eficácia, tornando a racionalidade como um mero fator instrumental. Partindo desse pressuposto, Maués (2016) refere que o Estado avaliador opera a partir das regulações que servem como parâmetros para definir políticas, para distribuir recursos e vigiar as instituições. Segundo a autora,

[...] são faces de uma mesma moeda, isto é, esses dois "momentos" se complementam e se realimentam, permitindo que as normas estabelecidas sejam cumpridas ou modificadas de acordo com os resultados alcançados e a importância que tenham para os interesses gerais da sociedade e o mercado, como um todo (MAUÉS, 2016, p. 447).

Na medida em que o Estado incorpora o papel de avaliador, em decorrência das características que assume a partir da reforma, passa a exercer um forte controle sobre as escolas, 
através de sistemas de avaliação que objetivam "amarrar os conteúdos ensinados, estabelecendo metas que, caso sejam atingidas, permitirão, na concepção dos reformadores, o alcance de melhor qualidade do ensino" (MAUÉS, 2016, p.446). No caso brasileiro, Krawczyk e Vieira (2012, p. 59), sintetizam que:

A União (governo federal) ficou, assim, responsável pela definição das diretrizes gerais para uma educação de qualidade e pela avaliação dos resultados, enquanto se ampliava a responsabilidade dos estados e municípios sobre a gestão e o provimento da educação à população em todos os níveis [...] em um processo de recentralização/descentralização, pelo qual o Estado concentrou a direção e o controle de todo o sistema e passou a partilhar o provimento desse serviço com a sociedade.

Conforme mencionado, sob o Estado avaliador, os resultados tornam-se prioritários em relação ao processo. Além disso, a ideia básica presente nas reformas educativas, entre os anos 80 e 90, em consonância com os organismos internacionais, é que os sistemas de ensino devem se tornar mais diversificados e flexíveis, objetivando uma maior competitividade com contenção nos gastos públicos.

No cenário nacional, os anos 90 demarcaram o compartilhamento da responsabilidade da educação pública com a sociedade civil, resultando na reconfiguração de outra relação entre governo e comunidade. Nessa conjuntura, seguindo o modelo do Estado avaliador, são delegadas à escola responsabilidades "e sobre ela são operados sistemas de avaliação externa cujos resultados são submetidos a uma base de metas de qualidade demarcadas pelo centro" (SCHNEIDER, NARDI; DURLI, 2018, p.119).

Com a instituição das reformas e a implementação de instrumentos de controle no padrão das avaliações, o Estado passa a promover a regulação da educação, assegurando a presença do paradigma dominante nas escolas, tanto públicas quanto privadas, de modo a controlar resultados e salvaguardar a eficiência (MAUÉS, 2010).

Nessa perspectiva, conforme referido, o cenário dos anos 90 do século XX é demarcado como período em que, no Brasil, a avaliação passa a ser obrigatória no sistema educacional. Desde então, as avaliações externas adquiriram centralidade até os dias atuais, como forma manter o controle do Estado sobre os processos educativos.

As interpretações que a pesquisa possibilitou

Com a intenção de pôr em tela a produção candente da área educacional, concentramnos na análise das principais tendências investigativas sobre a avaliação educacional com base na produção do triênio 2015-2018.

O mapeamento consistiu na identificação dos periódicos cujo foco sinalizasse a "avaliação 
educacional" como uma das temáticas de sua publicação, abrindo caminho para a organização de um quadro que evidenciasse a recorrência de trabalhos na área. Assim, de um universo de 423 trabalhos identificados, foram selecionados 102 os quais atendiam aos critérios da pesquisa. Nessa etapa, foi possível identificar dois grandes eixos , a saber: o eixo avaliação da educação básica e avaliação do ensino superior.

Segundo a especificação dos trabalhos levantados o eixo Avaliação da comporta três domínios temáticos com certo equilíbrio no quantitativo de trabalhos publicados no período: a) avaliação das aprendizagens na educação básica; b) avaliação institucional da educação básica e; c) avaliação dos sistemas de ensino da educação básica, os quais abrangem 63 trabalhos.

No tocante ao eixo Avaliação da Educação Superior, identificamos dois domínios temáticos: a) a internacionalização do ensino superior e, b) as políticas de avaliação no ensino superior, totalizando 39 trabalhos.

Como características gerais é possível destacar a prevalência de trabalhos no domínio temático "internacionalização do ensino superior" o qual contemplou $26 \%$ dos trabalhos. Esse resultado está em consonância com os dados da pesquisa de Morosini e Nascimento (2017, p.02), os quais demonstram que, no Brasil, "a internacionalização da educação superior vem se constituindo em um dos principais motes da universidade na contemporaneidade". Já a "avaliação institucional da educação básica" ocupa o segundo lugar com $24 \%$ das produções, como o próprio nome indica, a avaliação institucional refere-se à avaliação de instituições de ensino, estendendose aos sistemas educativos, às políticas e programas. Barreto e Novaes (2016, p. 316), atestam ser uma tendência investigativa na área afirmando que, "apenas nos anos mais recentes, a avaliação institucional começa a ser disseminada nas redes municipais de ensino de todas as regiões do País".

Com relação à "avaliação das aprendizagens na educação básica", representa 20\%, sendo que destes, apenas cinco indicam que a avaliação da aprendizagem possui uma visão formativa; outros oito trabalhos revelam que não houve profundas mudanças na avaliação da aprendizagem, sendo que de acordo com os trabalhos, a visão positivista da avaliação é a que permanece nas escolas. Esse fato também é apresentado por Calderón e Poltronieri (2013), onde detectaram em $59 \%$ dos trabalhos analisados apresentam essa mesma concepção de avaliação. No tocante ás "políticas de avaliação do ensino superior" um número menor de trabalhos foi levantado 17\%, sendo que os estudos nos apresentam que há uma massificação das políticas de avaliação, que agem sob a lógica neoliberal pressionando as instituições de ensino superior.

Já o domínio temático referente à avaliação dos sistemas de ensino da educação básica 
correspondeu ao menor número de trabalhos, representando $13 \%$, os quais indicam ser "processos uniformizados, centralizados e quantitativos" sendo resultados de "iniciativas recentes e mais pronunciadas que estimulam o uso dos resultados obtidos, buscando induzir mudanças no trabalho do professor e no cotidiano das instituições de ensino [...] o que tendencialmente produz a imobilidade e a padronização dos sistemas educacionais" (MINHOTO, 2016, p.88).

Entre os trabalhos correspondentes aos dois eixos de análise, prevalecem análises sobre as reformas educacionais que influenciadas pela reforma do Estado, resultaram no desenvolvimento de políticas educacionais sintonizadas com a ideologia neoliberal. Alguns temas que permeiam os trabalhos e merecem destaque: avaliação educacional em larga escala, avaliação educacional em contextos municipais, função docente e avaliação, formação de professores e avaliação, avaliação da qualidade educacional, rankings educacionais, indicadores educacionais. Esses temas são recorrentes em ambos os eixos e sugerem um avanço nas teorias relativas à avaliação educacional, no entanto, em seus achados, indicam a prevalência da prática avaliativa aliada a uma avaliação positivista e coercitiva. Portanto, salientamos que para sustentação teórica dos dois eixos que serão apresentados a seguir, serão utilizados os autores mais citados entre os trabalhos, ou seja, utilizaremos como estofo teórico os autores que são referência na área da avaliação da educação básica e da avaliação da educação superior.

\section{Avaliação na educação básica}

O eixo Avaliação da Educação Básica corresponde a $62 \%$ dos trabalhos levantados na pesquisa. A leitura dos mesmos nos permitiu a aproximação com temas que estão em evidência nas pesquisas sobre avaliação escolar, que foram divididos em três domínios temáticos: a) avaliação das aprendizagens da educação básica; b) avaliação institucional da educação básica e, c) avaliação dos sistemas de ensino da educação básica; neles, podemos indicar ainda, a utilização de autores que são referência na área: Cipriano Luckesi (22 trabalhos), seguido por José Carlos Libâneo (18 trabalhos) e Jussara Hoffman (15 trabalhos), além de outros autores que também transitam nesses temas, como Demerval Saviani e Bernardete Gatti. Sendo assim, priorizaremos nesta análise trazer discussões dos autores que são referência na área e em alguns momentos a entrada dos trabalhos analisados.

Em geral, as discussões processadas nos trabalhos corroboram com as reflexões de Saviani (2007), segundo as quais há uma agenda global da qual o Brasil tem feito parte, predominando o imperativo da produção de resultados, informados por índices oficiais. É nessa 
direção que o autor advertiu:

À luz dessa constatação, foram estabelecidas metas progressivas de melhoria desse índice, prevendo-se atingir, em 2022, a média de 6,0 índice obtido pelos países da Organização para Cooperação e Desenvolvimento Econômico (OCDE), que ficaram entre os $20 \mathrm{com}$ maior desenvolvimento educacional do mundo. 0 ano de 2022 foi definido não apenas em razão da progressividade das metas, mas à vista do caráter simbólico representado pela comemoração dos 200 anos da Independência política do Brasil (SAVIANI, 2007, p.1234).

Geralmente, quando falamos em avaliação educacional a associamos com desempenho dos alunos. Não por acaso, pois esta é a modalidade presente no dia a dia das pessoas e, para Gatti (2002, p. 18),

Foi essa a cultura que se desenvolveu em torno dos processos avaliativos no cotidiano escolar e que, apesar das amplas discussões sobre a questão, permanece até hoje, tendo deixado uma forte marca na vida das pessoas e na representação que fazem da avaliação. Então, o fato de os processos avaliativos estarem sempre presentes no ambiente escolar, em todos os níveis, faz com que as pessoas se reportem de imediato a esse tipo de avaliação quando se fala em avaliação educacional, restringindo seu significado.

De acordo com Gatti (2002, p.17), na contemporaneidade, "a avaliação educacional não se reduz a um campo com teorias, processos e métodos específicos, mas também um campo abrangente que comporta subáreas com características específicas". Foi essa percepção que, a propósito, nos possibilitou identificar os três domínios temáticos consideradas candentes, segundo o universo de trabalhos sobre avaliação da educação básica publicados no triênio 2015-2018.

De acordo com Saviani (2007), a luta pela qualidade da educação pública inicia na década de 20, com a fundação da Associação Brasileira de Educação ( $A B E)$, tempo em que esse tema "ganha visibilidade através do Manifesto dos Pioneiros da Educação Nova, em 1932, e com a Campanha em Defesa da Escola Pública, na virada da década de 50 para os anos 60, na fase final da tramitação do projeto de LDB" (p.1243). Os educadores continuam com as Conferências Brasileiras de Educação, na década de 80, e com o Fórum Nacional em Defesa da Escola Pública na Constituinte e na nova Lei de Diretrizes e Bases da Educação Nacional (LDBEN, 9394/1996), nos anos 90.

No contexto dos anos 90 do século XX, o Brasil investiu fortemente em sistemas de avaliação da educação básica, década em que ocorreu a implantação do Sistema de Avaliação da Educação (SAEB), resultando em avaliações em larga escala, por meio de exames nacionais padronizados. Com isso, sobressaíram indicadores objetivos não apenas sobre o acesso à escola, mas também sobre o desempenho dos estudantes. Através desse sistema, tornou-se possível a comparação entre escolas, redes e unidades da federação.

Hoffmann (2009), questiona a capacidade desses sistemas avaliativos que garantem a 
melhoria na qualidade do ensino. De acordo com a autora, a crença popular é que as escolas tradicionais são mais exigentes que as escolas inovadoras, sendo consideradas mais eficazes para a garantia de um ensino de qualidade; trocando em miúdos, a ideia é simples: quanto maior a nota, melhor é o aprendizado do aluno.

Portanto para a autora, temos um sistema de avaliação vago, porque não é capaz de apontar as falhas no processo de aprendizado dos alunos e nas práticas dos (a) professores e professoras, a prova disso são as estatísticas que se mostram negativas em relação à realidade brasileira. Aos estudantes cabe responder os questionamentos feitos pelo professor através do livro didático o que resulta apenas na memorização, obediência e passividade, características da pedagogia tradicional e tecnicista. Quem afirma essa condição são os próprios dados do SAEB divulgados pelo Ministério da Educação (MEC) em 2017, onde constatou que sete de cada dez alunos do terceiro ano do ensino médio tem nível insuficiente em português e matemática. A partir destes dados, Minhoto (2016, p.82) afirma:

\footnotetext{
A constante aplicação de testes padronizados tende a pressionar, enrijecer e induzir a redução da amplitude e variedade dos currículos escolares e a produzir, entre as escolas, estratégias que não propiciam elevação no nível de qualidade do processo educacional, mas encobrem os resultados por meio da omissão (ou mesmo exclusão) de alunos que apresentam baixa proficiência.
}

De acordo com Méndez (2002) a avaliação formativa não deveria estabelecer relações com a perspectiva da avaliação domesticadora pois ela é sinônimo de avaliar para excluir, sobretudo através dos testes padronizados que compatibilizam com a dimensão sancionadora (castigo e controle) das práticas de exames.

Em conformidade com os autores (DIAS SOBRINHO, 2010; HOFFMANN, 2009; LUCKESI,1995; MAUÉS, 2016a; MÉNDEZ, 2002) a avaliação das aprendizagens não pode ser vista de forma dissociada do processo de ensino e aprendizagem, sendo considerada peça fundamental do currículo, dos sistemas de ensino e das políticas educacionais. Todavia, os achados recorrentes do eixo Avaliação da Educação Básica referem sobremaneira à avaliação das aprendizagens relacionando-a com os exames externos, destacada a introdução deles pelo viés da política internacional, a inobservância dos contextos regionais e locais e a realidade das escolas. Para Luckesi (2000, p. 8),

A avaliação da aprendizagem não é e não pode continuar sendo a tirana da prática educativa, que ameaça e submete a todos. Chega de confundir avaliação da aprendizagem com exames. A avaliação da aprendizagem, por ser avaliação, é amorosa, inclusiva, dinâmica e construtiva, diversa dos exames, que não são amorosos, são excludentes, não são construtivos, mas classificatórios. A avaliação 
inclui, traz para dentro; os exames selecionam, excluem, marginalizam.

Sob as políticas de produção e de regulação por resultados, a avaliação na educação básica vem sendo compelida a submeter-se às matrizes de referência dos exames externos, realizados em larga escala no país, subtraindo possibilidades e potencialidades da avaliação em contextos curriculares sintonizados com projetos educativos escolares, regionais e nacional. Os resultados dos trabalhos examinados indicam, portanto, que há uma sujeição das avaliações do contexto escolar à lógica dos exames externos, no sentido de que aquelas operam em função destes, tendo em vista uma maior segurança dos professores e das instituições escolares na produção de resultados de desempenho dos estudantes, conforme podemos constatar no estudo de Cunha e Muller (2018, p.146),

As avaliações externas têm servido como parâmetro para a prática pedagógica desenvolvida com os estudantes. As atividades mecanizadas pautadas por matriz de referência e seus descritores tem, por vezes, o mero intuito de alcançar melhores índices, distanciando-se da formação dos sujeitos com consciência crítica [...] as avaliações externas acabam tornando-se o currículo da escola.

Para Saviani (2007), esse modelo de avaliação constitui problema crucial no contexto atual. Segundo o autor, o modelo de avaliação assumido pelo MEC não está centrado em pesquisas sobre a situação da educação brasileira, pois sua inspiração vem dos instrumentos internacionais focados na mensuração de resultados.

Há, também, a avaliação institucional da escola básica, que ainda não se constituiu como uma prática coerente da educação brasileira, pois a padronização da avaliação externa, de que são exemplos a Prova Brasil e o Índice de Desenvolvimento da Educação Básica (IDEB), desprestigiam a avaliação interna. Importa assinalar que uma das abordagens da avaliação institucional que costumeiramente se apresenta nas escolas é aquela ordenada pelo Estado, ou seja, o Estado desempenha o papel de avaliador externo, um Estado Avaliador que controla e monitora o desempenho das escolas e dos sistemas de ensino (BRANDALISE, 2010).

Portanto, a partir da leitura das considerações finais dos trabalhos que correspondem ao domínio temático da avaliação institucional, o que chama a atenção é a necessidade de mudança desse sistema avaliativo. Esse breve panorama, traçado com base nos debates constantes dos trabalhos consultados, realça o papel controlador do Estado sob os sistemas de ensino, e, consequentemente, sobre a avaliação das aprendizagens e a avaliação institucional da educação básica.

Em face disso, será possível uma saída pedagógica que aposte na superação desta polarização? Para Libâneo (2006), os processos educativos possuem um caráter endógeno, de 
dentro para fora, e, por essa razão, há possibilidades para se repensar a avaliação educacional. Uma delas é a construção de políticas educacionais que tenham em sua base a realidade escolar e a preocupação com aprendizagem dos alunos, de modo a serem promovidas modificações internas nas escolas.

Libâneo (2006), destaca que é comum pensar a escola de cima para baixo, primeiro se considera os currículos, depois as metodologias e, finalmente, se espera os resultados. Segundo o autor, frente a esse descompasso e com a onda de novas tecnologias, é imprescindível pensarmos na diversidade social e cultural dos alunos. Assim sendo, os estudos correspondentes ao eixo avaliação da Educação Básica do triênio 2015-2018, nos sugerem que a avaliação educacional tem se firmado cada vez mais como elemento de regulação e da administração gerencial do Estado avaliador. Diante dessa dicotomia, corroborando com Libâneo (2006) questionamos: é possível prover aulas com conteúdos científicos sem deslegitimar os discursos dos alunos a partir de seus contextos de vida?

\section{Avaliação da educação superior}

O eixo Avaliação da Educação Superior, que comportou $38 \%$ do universo dos trabalhos identificados, compreendeu, a dois domínios temáticos: Internacionalização e Políticas de Avaliação. As discussões travadas nos trabalhos mapeados se servem, basicamente, das contribuições de autores como Dias Sobrinho (10 trabalhos), Adolfo-Ignácio Calderón (07 trabalhos), José dos Reis da Silva Junior (8 trabalhos), Valdemar Sguissardi (07 trabalhos), Olgaíses Cabra Maués (06 trabalhos).

De modo geral, Dias Sobrinho (2010) e Maués (2009) flagram que os governos estão procedendo, por meio de seus sistemas de avaliação, a uma classificação de programas, de cursos ou de instituições, cujos desempenhos são comparados, fator a fator, alimentando um ranking.

Considerada "ferramenta principal da organização e implementação das reformas educacionais" (DIAS SOBRINHO, 2010, p.195), as políticas de avaliação da educação superior fazem parte das complexas metamorfoses que a sociedade, a economia e a política enfrentam nas últimas décadas. Uma das grandes transformações que marcou o território nacional foi a entrada de jovens de diferentes classes sociais na educação superior. Para atender a essa pluralidade, o governo estimulou a expansão de vagas pela iniciativa privada, facilitando a abertura de inúmeras instituições, também com características diferenciadas "quanto à imagem social, 
duração de cursos, qualidade de serviços educativos, preços e estilos administrativos e organizacionais" (DIAS SOBRINHO, 2010, p.199).

A classe empresarial toma a educação superior como uma possibilidade de negócio e expansão do capital, aproveitando-se das concessões do governo, que abre mão de sua responsabilidade prover condições estruturais e financiamento público. Segundo Dias Sobrinho (2010, p. 200),

\begin{abstract}
O segmento mercantil da educação superior passou a tratar o estudante como cliente e a intensificar no sistema as lógicas de mercado: competitividade, custo-benefício, lucro, venda de serviços, oferta transnacional e virtual etc. Por sua vez, o estudante dessas instituições, agora transformado em consumidor, passou a ter ampla gama de opções de ofertas de serviços educativos e a poder escolher o curso que se coaduna com seus interesses e recursos, objetivando obter o título ou o diploma que the dê melhores condições para competir na faixa do mercado que corresponde às suas expectativas e possibilidades.
\end{abstract}

Esse fenômeno não constitui especificidade apenas do Brasil, Krawczyk e Vieira (2012), relatam que outros países da América Latina enfrentam essas transformações e que, em sua maioria, seguem orientações e agendas de organismos internacionais, sobretudo do Banco Mundial (BM), Fundo Monetário Internacional (FMI) e Organização para a Cooperação e o Desenvolvimento Econômico (OCDE), que agem nas instituições de ensino como agentes facilitadores da hegemonia neoliberal.

Para Maués (2009), o interesse desses organismos está relacionado à visão utilitarista da educação, como ferramenta que pode favorecer o desenvolvimento econômico, através da formação de "capital humano" que possa atender aos interesses do mercado. A preocupação com a formação profissional passou a ser uma constante nas agendas dos diferentes países e nas reformas empreendidas, com objetivo de operacionalizar os objetivos pretendidos pelo processo de mundialização do capital. Os interesses dos organismos internacionais desconsideram a educação superior como direito social, mas, a consideram como um bem privado "[...] espécie de quase mercadoria no quase mercado educacional" (SGUISSARDI, 2008, p. 49).

Paralelamente à introdução de alterações nos sistemas de avaliação, a partir dos anos 90 do século XX, foram introduzidos novos mecanismos de controle na educação superior, como os indicadores de desempenho, mecanismos de financiamento e medições da qualidade acadêmica. No Brasil, esta ação ocorreu por meio do Sistema Nacional de Avaliação da Educação Superior (SINAES) que assumiu a função reguladora, conforme a sua proposta de avaliação da educação superior.

Nesse sentido, a avaliação é levada a cumprir um importante papel na "funcionalização econômica da educação superior, nos conceitos e metodologias mais apropriados ao mercado, 
especialmente nas funções operacionais e pragmáticas de capacitação técnica para os empregos [...]" (DIAS SOBRINHO, 2010, p. 201). A partir das reformas implementadas a avaliação tornou-se um importante instrumento aliado ao mercado, pois tem como principal objetivo informar sobre a qualidade e tipo de profissional que os cursos oferecem, além de indicar as Instituições de Educação Superior (IES) que estão mais alinhadas às exigências da economia.

A racionalidade tecnocrática impressa pelas orientações de organismos multilaterais concede a avaliação educacional uma função controladora, pois, assume a tarefa de divulgar informações objetivas tanto para a administração central como os futuros consumidores do sistema educacional superior (DIAS SOBRINHO, 2010). Aqui vale destacar as políticas de avalição que passaram a prevalecer sobre as questões pedagógicas, entre os estudos destaca-se a legitimação de um ranking das IES, a partir das políticas avaliativas.

Com a alteração dos sistemas de avaliação, paralelamente ocorreu à introdução de novos mecanismos de controle, como os indicadores de desempenho, mecanismos de financiamento da qualidade acadêmica. Como desdobramento desse processo avaliativo, ocorrem profundas.

\begin{abstract}
[...] mudanças na identidade e na função social da universidade, que passa por um processo de clara metamorfose institucional, ao ser alocada no setor de prestação de serviços e, ao mesmo tempo, que passa a ser entendida, não mais como instituição historicamente autônoma em relação ao Estado e ao mercado, mas, agora, como organização social, heterônoma, resultando em novas formas de adequação ao mercado [...] (DOURADO, 2002, p. 245).
\end{abstract}

Ainda, de acordo com Chauí (1999, p. 222),

Essa universidade não forma e não cria pensamento, despoja a linguagem de sentido, densidade e mistério, destrói a curiosidade e a admiração que levam à descoberta do novo, anula toda pretensão de transformação histórica como ação consciente dos seres humanos em condições materiais determinadas.

De acordo com Maués (2009), desde a promulgação da LDBEN $n^{0}$ 9.394/06, que possibilitou a instauração de novas políticas e formas regulações, a legislação abriu possibilidade para que a formação em nível superior ocorresse em outros espaços, que não necessariamente a universidade. Ou seja, a formação universitária se deu/dá fora da universidade, por vezes com baixa qualidade, sobretudo pelo aumento de entidades privadas que começaram a surgir em razão da facilidade propiciada pela legislação, que estimulou múltiplas maneiras de formação, através de cursos aligeirados e carga horária reduzida, inaugurando o que Sguissardi (2008), chamou de privado-mercantil.

A partir das análises dos trabalhos, e em consonância com os dados levantados no trabalho de Guedes, Muranaka e Aragão (2016, p.118), com os autores que são referência na 
área, observa-se como resultado das políticas de avaliação neoliberais,

A diversificação das IES, o crescimento do setor privado da educação superior, cujos dados permitem afirmar a tendência à privatização da educação superior brasileira. Esse processo teve como consequência a transformação do direito à educação em serviço a ser comprado no mercado, corroborando os pressupostos neoliberais de que o mercado é o único caminho que garante a liberdade de escolha dos indivíduos.

Nesse contexto, marcado pela mercantilização, o processo de internacionalização é estimulado, na medida em que é considerado a possibilidade de ampliação do mercado, pela terceirização de mão de obra e pela inovação tecnológica (SGUISSARDI, 2008). Ainda considerando esse cenário, a internacionalização da educação superior passa a assumir o papel de produtora de conhecimentos geradores de valor econômico, ou seja, está voltada aos interesses do mercado.

Segundo entendem Maués e Bastos (2016, p. 713), a internacionalização da educação superior está associada a alguns fatores fundamentais, dentre os quais,

[...] a transformação da educação em um serviço comercial, atraindo o interesse crescente do empresariado, que transforma essa mercadoria altamente cobiçada em moeda básica para a construção da sociedade do conhecimento; a construção do espaço econômico da Europa, que estimulou a criação do Processo de Bolonha, o que veio facilitar a mobilidade de estudantes, professores no interior de um país e entre países, ampliando ou até mesmo rompendo qualquer fronteira do conhecimento; a transformação da educação em uma força produtiva que passa a ser disputada com fins econômicos, como ferramenta para a ampliação do processo de acumulação; 0 papel do Banco Mundial ao transformar a Educação Superior em ensino terciário na busca de formar homens e mulheres aptos a construírem a sociedade do conhecimento.

Os trabalhos que versam sobre a internacionalização da educação, entre eles Morosini e Corte (2018), Maués e Bastos (2016), demonstram que globalização e internacionalização são conceitos que dialogam, historicamente, desta forma, compreendemos que o fenômeno da globalização repercute nos modos de pensar, regularizar e gestar a educação superior, seja no contexto global ou local. Morosini e Corte (2018, p.104), constataram de forma unanime a necessidade das instituições de educação superior investirem em processos de internacionalização, no entanto, tal perspectiva "está fortemente relacionada aos ditames da globalização e do desenvolvimento econômico das nações".

A partir da leitura das considerações finais dos trabalhos mapeados e das contribuições de Morosini e Corte (2018), Maués e Bastos (2016), nos chamou a atenção o fato de que a internacionalização se constitui um movimento que nasce no contexto da sociedade globalizada e que requer envolvimento e compreensão acerca dos múltiplos fatores que interferem nas relações 
político-pedagógicas. Além disso, a internacionalização da educação superior está diretamente relacionada com a ampliação "[...] do monopólio do conhecimento e de produção tecnológica, ganha cada vez mais visibilidade passando a desempenhar um papel de produtora de conhecimento que agregue um valor econômico" (MOROSINI; CORTE, 2018, p.116).

Em outras palavras, a educação considerada força produtiva, passa a ser utilizada como um instrumento em favor do capitalismo. O professor assume papel fundamental nesse processo, razão pela qual os organismos internacionais manifestam preocupação com a formação desse profissional, realizando recomendações e sugestões ao passo que atribuem a esses profissionais a responsabilidade pela qualidade da educação (MAUÉS; BASTOS, 2016).

Portanto, ao analisar as tendências dos estudos da área sobre avaliação na educação superior, publicados no triênio 2015-2018, constatamos que assim como as políticas de avaliação a internacionalização da educação superior também se constituiu na arena do capitalismo, que ora transparece e ora oculta sua verdadeira essência, o que desfavorece a qualidade e o acesso ao ensino superior.

\section{Considerações finais}

Neste trabalho, tomamos por base dois eixos temáticos, definidos em razão dos achados da pesquisa, eixos esses claramente identificadores de uma maior recorrência dos estudos sobre avaliação educacional na educação básica, publicados no período 2015 a 2018. A partir deles foi possível traçar uma síntese sobre os achados, que parecem apontar para uma mesma direção: avaliar é preciso. Porém, na extensão dessa afirmação, despontam questionamentos: 0 que avaliar? Como avaliar? Como ficam as diferenças culturais, socioeconômicas, físicas e cognitivas em um contexto de ascensão de políticas de avaliação externa e em larga escala?

A partir das análises possibilitadas neste estudo, foi possível constatar que a avaliação educacional vem sendo ancorada em uma lógica mercantilista, por meio da valorização dos instrumentos de avaliação externa e em larga escala, consoante às orientações de organismos internacionais. Por outro lado, não podemos desconsiderar as determinações históricas, sobre as quais os sistemas avaliativos foram forjados, atendendo ao propósito dos governos na obtenção de resultados.

De acordo com os achados da pesquisa, transparece a necessidade de se construir um conceito que abarque o contexto local das instituições para se analisar a qualidade da educação, resultado de um processo de reflexão e questionamento, que não submeta a avaliação à condição 
de instrumento meramente técnico. Essa indicação está presente tanto nos estudos que tratam da avaliação da educação básica quanto dos filiados ao eixo Avaliação da Educação Superior.

No primeiro eixo Avaliação da Educação Básica, os trabalhos demonstram preocupação com os processos avaliativos escolares que se sustentam em instrumentos técnicos e objetivos, destacam a implicação de fatores internos e externos que trabalham para a manutenção desse sistema, entre eles a mídia com notória valorização de resultados educacionais finais. Já, no que diz respeito ao eixo Avaliação da Educação Superior, os estudos apontam para a necessidade de refletirmos criticamente sobre a formação profissional ali processada, além de considerar as estruturas neoliberais que também moldam os processos de avaliação.

De modo geral, identificamos que as demandas globais, relacionadas as imposições do sistema capitalista impactam o campo da avaliação educacional, agindo como instrumento de controle e coerção. Destacamos ainda, a partir da abundância de trabalhos na área, apelos à mudança nos sistemas avaliativos, tanto da educação básica, quanto da educação superior, mas na grande maioria dos trabalhos, sugere-se uma mudança de cima para baixo, ou seja, dos agentes internacionais (global) para as instituições de ensino (local).

No entanto, acreditamos que pode haver uma mudança local (educação básica e superior), iniciando de baixo para cima, no sentido de provocar a desestabilização das agências que fomentam as políticas públicas baseadas no sistema capitalista, visando apenas os resultados por eles mesmos, sem valorar o processo de ensino-aprendizado.

\section{REFERÊNCIAS}

ALMEIDA JÚNIOR, Vicente de P. A avaliação da educação superior no contexto das políticas educacionais. In: RISTOFF, Dilvo.; DIAS SOBRINHO, José. (Orgs.) Avaliação democrática. Florianópolis: Insular, 2001. p. 27-33.

BARRETTO, Elba Siqueira de Sá; NOVAES, Gláucia T. Franco. Avaliação institucional na educação básica: retrospectiva e questionamentos. Est. Aval. Educ., São Paulo, v. 27, n. 65, p. 314-345, maio/ago. 2016

BARROS, João. O Estado, a educação e a regulação das políticas públicas. Educação \& Sociedade, Campinas, v.26, n.92, esp. p.725-751, out. 2005.

BEHRING, Elaine Rossetti. Brasil em contra-reforma: desestruturação do Estado e perda de direitos. 2 ed. São Paulo, Cortez, 2008.

BRASIL. Ministério da Administração Federal e Reforma do Estado. Plano diretor da reforma do aparelho do Estado. Brasília, DF: Imprensa Nacional, 1995. 
BRASIL. Coordenação de Aperfeiçoamento de Pessoal de Nível Superior. Ofício Circular $\mathrm{n}^{0}$ 23/2015 - DAV/CAPES. Disponível em: . Acesso em: 01 setembro. 2018.

BRANDALISE, Mary Ângela Teixeira. Avaliação institucional da escola: conceitos, contextos e práticas. Olhar de professor, Ponta Grossa, p. 315-330. Mar, 2010.

BRESSER-PEREIRA, Luiz Carlos. Democracia, estado social e reforma gerencial. Revista administração de empresas. São Paulo, v. 50, n. 1, p. 112-116. Mar. 2010.

CALDERÓN, Adolfo Ignácio; POLTRONIERI, Heloisa. Avaliação da aprendizagem na Educação Básica: as pesquisas do estado da arte em questão (1980-2007). Revista Diálogo Educacional. Curitiba, v.13, n. 40, p. 873-893, set./dez. 2013

CHAUÍ, Marilena. A universidade em ruínas. In: TRINDADE, H. (Org.). Universidade em ruínas na república dos professores. Petrópolis: Vozes; Porto Alegre: CIPEDES, 1999.

CUNHA, Eduardo Carlos Souza; MULLER, Eucinéia Regina. Avaliações em larga escala: uma tentativa de controle, regulação, captura e padronização do cotidiano escolar. Cadernos da Fucamp, v.17, n.29, p. $143-163 / 2018$.

DEMO, Pedro. Avaliação qualitativa. 5. ed. Campinas, São Paulo: Autores Associados, 1995.

DIAS SOBRINHO, José. Avaliação e transformações da educação superior brasileira (1995-2009): do provão ao Sinaes. Avaliação Campinas, Sorocaba, v. 15, n. 1, p. 195-224, Mar. 2010 .

DOURADO, Luiz Fernandes. Reforma do Estado e as Políticas para a Educação Superior no Brasil nos anos 90. Educação \& Sociedade, Campinas, v. 23, n. 80, p. 234-252. Set. 2002.

FELIX ,Glades Tereza; BERTOLIN, Julio Godoy; POLIDORI, Marlis Morosini. Avaliação da educação superior: um comparativo dos instrumentos de regulação entre Brasil e Portugal. Avaliação, Campinas; Sorocaba, v. 22, n. 1, p. 35-54. Mar. 2017.

GATTI, Bernardete. Avaliação educacional no Brasil: pontuando uma história de ações EccoS Revista Científica, São Paulo, v. 4, n. 1, p. 17-41. Jun. 2002.

GUEDES, Maria Denise; MURANAKA, Maria Aparecida Segatto; ARAGÃO, José Euzébio de Oliveira Souza. Políticas de avaliação da educação superior no Brasil de FHC a Lula: uma análise crítica dos seus pressupostos e fundamentos (p. 103-122). Revista de Ciências da Educação, [S.I.], jun. 2016

HOFFMANN, Jussara. Avaliação mediadora: uma prática em construção da pré-escola à universidade. Porto Alegre: Mediação, 2009.

KRAWCZYK, Nora Rut; VIEIRA, Veral Lúcia. Uma perspectiva histórico-sociológica da reforma educacional na América Latina: Argentina, Brasil, Chile e Méxino nos anos 1990. Brasília: Liber Livro, 2012.

LESSARD, C. Universidade e a formação profissional dos docentes: novos questionamentos. Educação \& Sociedade, Campinas, v. 27, n. 94. p. 201-227, jan./abr. 2006. 
LIBÂNEO, José Carlos. Sistema de ensino, escola, sala de aula: onde se produz a qualidade das aprendizagens? In: LOPES, Alice Casimiro; MACEDO, Elizabeth.(Org.) Políticas de currículo em múltiplos contextos. São Paulo: Cortez, 2006. p. 70-125.

LUCKESI, Cipriano. Avaliação educacional escolar: para além do autoritarismo. In: Avaliação da aprendizagem escolar: estudos e proposições. São Paulo: Cortez, 1995. (Org.).

LUCKESI, Cipriano. O que é mesmo o ato de avaliar a aprendizagem? Pátio, Porto Alegre, n.12, ano 3, p.6-11, fev./abr. 2000

MAUÉS, Olgaíses Cabral. As políticas de avaliação da educação superior, o trabalho docente e a cultura acadêmica: as possíveis relações. Projeto de Pesquisa financiado pelo CNPq, 2009.

MAUÉS, Olgaíses Cabral. A avaliação e a regulação: o professor e a responsabilização pelos resultados. In: DALBEN, Ângela Imaculada Loureiro de Freitas (et al.). Convergências e tensões no campo da formação e do trabalho docente. Coleção Didática e Prática de Ensino. Belo Horizonte: Autêntica, 2010. p. 703-729.

MAUÉS, Olgaíses Cabral. As políticas de avaliação da educação básica e o trabalho docente. Linhas Críticas, Brasília, DF, v.22, n.48, p. 442-461, 2016 a.

MAUÉS, Olgaíses Cabral; BASTOS, Robson dos Santos. As políticas de educação superior na esteira dos organismos internacionais. Revista Brasileira de Política e Administração da Educação, Goiânia, v. 32, n. 3, p. 699 - 717,Set/Dez. 2016b.

MAROY, Christian; DUPRIEZ, V. La régulation dans les systèmes scolaires: proposition théorique et analyse du cadre structurel en Belgique francophone. Revue Française de Pédagogie, Paris, n. 130, p. 73-87, jan./mar. 2000.

MAROY, Christian. Vers une régulation postbureaucratique des systèmes d'enseignement en Europe? Sociologie et Sociétés, v. 40, n. 1, p. 31-5, 2008.

MÉNDEZ, Juan Manuel Álvares. Avaliar para conhecer, examinar para excluir. Porto Alegre: Artmed, 2002.

MINHOTO, Maria Angélica Pedra. Política de Avaliação da Educação Brasileira: limites e perspectivas. Jornal de políticas educacionais. v.10, n.19. Jan-Jun de 2016, p. 77-90.

MOROSINI, Marília Costa; NASCIMENTO, Lorena Machado do. Internacionalização da educação superior no brasil: a produção recente em teses e dissertações. Educação em Revista. Belo Horizonte, v. 33, Fev. 2017.

MOROSINI, Marília Costa; CORTE, M. Teses e realidades no contexto da internacionalização da educação superior no Brasil. Revista Educação em Questão, v. 56, n. 47, p. 97-120, 12 abr. 2018.

SIMIONATTO, Ivete. LUZA, Edinaura. Estado e sociedade civil em tempos de contrarreforma: lógica perversa para as políticas públicas. Textos \& Contextos, Porto Alegre, v.10, n.2, p.215226, dez. 2011 
SAVIANI, Dermeval. O Plano de Desenvolvimento da Educação: análise do projeto do MEC. Educação \& Sociedade, Campinas, v. 28, n. 100, p. 1231-1255, 2007.

SCHNEIDER, Marilda Pasqual; NARDI, Elton Luiz; DURLI, Zenilde. Políticas de Avaliação e Regulação da qualidade: repercussões aa Educação Básica. Revista e-Curriculum, São Paulo, v.16, n.1, p. 109-138, Jan/Mar. 2018.

SGUISSARDI, Valdemar. Modelo de expansão da educação superior no Brasil: predomínio privado/mercantil e desafios para a regulação e a formação universitária. Educação \& Sociedade, Campinas, v. 29, n. 105, p. 991-1022, set./dez. 2008.

GOMES, Luiz Gomes Ferreira. Novela e sociedade no Brasil. Niterói: EdUFF, 1998.

GURGEL, Carlos. Reforma do Estado e segurança pública. Política e Administração, Rio de Janeiro, v. 3, n. 2, p. 15-21, set. 1997.

\section{Agradecimentos}

O presente trabalho foi realizado com apoio da Coordenação de Aperfeiçoamento de Pessoal de Nível Superior - Brasil (CAPES) - Código de Financiamento 001. 